\title{
Knowledge, Attitudes, Beliefs and Perceived Risk of Acute Coronary Syndrome among Jordanian Patients
}

\author{
Nedal Alfasfos' ${ }^{1}$ Muhammad W. Darawad ${ }^{2}$, Basema Nofal'2, \\ Osama A. Samarkandi ${ }^{3}$, Basel Abdulqader ${ }^{4}$ \\ ${ }^{1}$ Faculty of Nursing, Alahliya Amman University, Balqa, Jordan \\ ${ }^{2}$ Faculty of Nursing, The University of Jordan, Amman, Jordan \\ ${ }^{3}$ Prince Sultan bin Abdulaziz College for Emergency Medical Services, King Saud University, Riyadh, KSA \\ ${ }^{4}$ California School of Health Sciences, Garden Groove, CA, USA \\ Email: rn_nedal@yahoo.com,m.darawad@ju.edu.jo,basemanofal@yahoo.com,osamarkandi@ksu.edu.sa, abasel_99@yahoo.com
}

How to cite this paper: Alfasfos, N., Darawad, M.W., Nofal, B., Samarkandi, O.A. and Abdulqader, B. (2016) Knowledge, Attitudes, Beliefs and Perceived Risk of Acute Coronary Syndrome among Jordanian $\mathrm{Pa}$ tients. Health, 8, 1830-1844.

http://dx.doi.org/10.4236/health.2016.815175

Received: September 29, 2016

Accepted: December 26, 2016

Published: December 29, 2016

Copyright $\odot 2016$ by authors and Scientific Research Publishing Inc. This work is licensed under the Creative Commons Attribution International License (CC BY 4.0).

http://creativecommons.org/licenses/by/4.0/

\section{(c) (i) Open Access}

\section{Abstract}

Background: Acute Coronary Syndrome (ACS)-associated mortality is considered high and still raising, where outcomes can be improved through immediate treatment initiation. Knowledge, attitudes, beliefs and perceived risk are cognitive factors that can affect patient's decision to seek care immediately. Therefore, this study aimed to explore knowledge, attitudes, beliefs, and perceived risk for future ACS event among Jordanian ACS patients. Methods: A descriptive, cross-sectional, correlational design was used to conveniently recruit 160 ACS patients from CCUs and medical floors at three Jordanian hospitals using the Modified ACS Response Questionnaire. Results: Almost, 65\% of participants had low level of ACS knowledge, specifically regarding untraditional ACS symptoms. Some negative attitudes and beliefs toward ACS were found. There was a moderate positive correlation between knowledge score and all of attitudes, beliefs and perceived risk score $(\mathrm{r}=0.549, \mathrm{p}<$ $0.01, \mathrm{r}=0.563, \mathrm{p}<0.01, \mathrm{r}=0.545, \mathrm{p}<0.01)$. Conclusion: Inadequate ACS knowledge, negative attitudes and beliefs toward ACS were associated with low perceived risk for future ACS event. Therefore, it is a priority to develop strategies that consider improving ACS patients' knowledge, attitudes, beliefs and perceived risk. This could be effective to enhance patient's decision to seek care and reduce ominous outcomes.

\section{Keywords}

Acute Coronary Syndrome, Knowledge, Attitudes, Jordan 


\section{Introduction}

Cardiovascular diseases (CVDs) are the major cause of death worldwide. They caused $40 \%$ of deaths in Europe [1] and $35.3 \%$ in the United States [2]. Similarly, the mortality of CVDs in the Middle East (ME) countries was reported among the highest worldwide [3]. Jordan falls in the ME region, in which $37.6 \%$ of deaths were related to CVDs [4]. Among CVDs is Coronary Heart Disease (CHD), a leading cause of death affecting cardiac vessels [2]. In Europe, CHD was reported as the most common cause of death, with 1.8 million annual deaths [1]. In the ME countries, CHD was responsible for $31.1 \%$ of deaths in Lebanon, $21.7 \%$ in Saudi Arabia, $17.4 \%$ in Syria, and $16.8 \%$ in Jordan [5]. Further, the Jordanian Ministry of Health [4] ranked CHD as the number one killer among CVDs in Jordan. The CHD is manifested through many clinical presentations called acute coronary syndrome (ACS) classified into: (a) ST-segment elevation myocardial infarction (STEMI), (b) non-STEMI (NSTEMI), or (c) unstable angina [2].

Alarmingly, about $50 \%$ of ACS patients die before hospital arrival [6]. This mortality can be reduced by quick reperfusion therapies using percutaneous coronary intervention or thrombolytic therapy [7]. The optimal benefits can be attained when definitive reperfusion is carried out within one hour of symptoms onset [8]. Literature showed that ACS patients were hesitant to immediately seek medical help [8] [9], where $82.8 \%$ of delay was related to patient's decision [9]. Patients who were hesitant to make immediate decisions for seeking help usually interpreted their symptoms as non-cardiac [10] [11]. This symptoms misinterpretation could be a factor that affects decision to seek care, which is related to poor knowledge of ACS symptoms or inappropriate adoption of attitudes and beliefs towards symptoms [12].

To promptly recognize ACS symptoms and seek care, patients should have knowledge about ACS [13]. Moser and colleagues [14] reported that patients who correctly attributed symptoms to the heart were faster to seek care than those who misinterpreted symptoms. Relying on patients' ACS knowledge and related symptoms is not enough to enhance seeking care [13]. Cognitive factors including attitudes and beliefs can also affect their decision [15]. Also, Hart [16] reported perceived risk for future event to be a factor that could help to improve decision to seek care.

The lack of understanding of ACS symptoms and improper symptoms attribution were significant factors to affect seeking care behavior. Also, a gap was found in knowledge among general public regarding ACS and its symptoms and the appropriate response [17]. A few studies investigated patient's knowledge about ACS symptoms [18] [19], which reported inadequate ACS knowledge among both patients and public. Dracup and colleagues [13] investigated ACS knowledge among 3522 patients. The mean score of patients' knowledge was $71 \%$, with $56 \%$ of participants having low level. Similar results were found among Irish patients (68.3\%) [19]. Another study conducted among 720 Pakistani patients found that the majority of patients were unable to recognize any ACS symptom [20]. Moreover, Henriksson and colleagues [18] found that both Swedish public and patients had inappropriate low ACS knowledge.

Few studies reported attitudes and beliefs toward ACS symptoms among patients. 
Dracup and colleagues [13] reported that participants' mean score of attitudes was 14.5 out of 20, and beliefs score was 22.75 out of 40. Also, O'Brien and colleagues [19] found patients' attitudes and beliefs towards ACS to be inappropriate with a mean score of 14.2 and 27, respectively. Henriksson and colleagues [21] reported the same lack of confidence to properly recognize and attribute ACS symptoms.

Patients' perception about being at risk to develop new ACS event is an important factor to enhance seeking care. A qualitative study evaluated patient's decision to seek care revealed that appropriate health seeking behaviors were reported by patients who considered themselves at risk for cardiac events [15]. In addition, Dracup and colleagues [13] reported that only 57\% of ACS patients considered themselves at risk for future events. The general public had low perceived risk for heart diseases [22]. Similarly, perceived risk for cardiac diseases was assessed among 1000 American women, where approximately $90 \%$ thought that heart problems are not female concern [23].

In Jordan, there is a need to understand what patients know about ACS symptoms, and what attitudes and beliefs they have toward these symptoms. According to our knowledge, studies in this regard are inadequate. Such programs can promote awareness and patients' decision to seek help earlier, and consequently improves patients' survival and reduce the economic burden of ACS. Therefore, this study aims to explore knowledge, attitudes, beliefs and perceived risk for future ACS event among Jordanian patients.

Research questions

1) What is the level of knowledge that Jordanian ACS patients have regarding ACS?

2) What are the attitudes and beliefs that Jordanian patients have toward ACS?

3) How do Jordanian patients with ACS perceive themselves as vulnerable for future ACS?

4) What are the relationships among knowledge, attitudes, beliefs and perceived risk and patient's demographic variables among Jordanian patients with ACS?

\section{Methodology}

Design: A cross-sectional survey design was adopted to collect data from Jordanian patients with ACS.

Setting: Hospitals were recruited from the middle region of Jordan, which contains $62 \%$ of population [24] and $72 \%$ of hospital beds in Jordan [25]. The healthcare system in Jordan is divided into four sectors including governmental, private, educational and military [25]. The eligibility criteria for selecting hospitals included large hospitals containing coronary care units (CCUs) using a cut-off point of 300 beds [26]. Then, random sampling was used to choose three large hospitals from the list of eligible hospitals, one hospital from each healthcare sector.

Sampling: The target population included Jordanian patients with ACS in Jordanian hospitals. Accessible population included Jordanian ACS patients in large-size hospitals in the middle region of Jordan. Consecutive patients with pre-decided eligibility criteria were selected from CCUs and medical floors. Patients were eligible if (a) had a con- 
firmed diagnosis of ACS; (b) were able to understand Arabic language; and (c) had a Jordanian nationality. Moreover, patients were excluded if (a) had impaired cognitive ability; (b) were hemodynamically unstable; or (c) lived in an institutional setting. The sample size was estimated using power analysis technique described by Cohen [27] using the following parameters; medium effect size, Power $=0.80, \alpha=0.05$, and applying the Analysis of Variance (ANOVA) test. The estimation revealed a minimum required sample size of 156 patients. However, a larger sample size was targeted to compensate for low response rate and questionnaires with missing values. A total of 270 invitees, only 160 agreed to participate (59\%).

Instrument: The study package had two parts. Part one contained demographic data sheet (age, gender, marital status, income, employment, medical diagnosis, insurance, and hospital type). Part two contained the Arabic version of the Modified ACS Response Questionnaire [28] that has three sections measuring ACS knowledge (26 items), attitudes (five 4-point Likert scale), beliefs (ten 4-point Likert scale) and perceived risk. Perceived risk is a separate subscale from beliefs section using a separate scoring system (one 5-point Likert scale ranging from $1=$ low risk to $5=$ high risk). The instrument was modified from "Response Questionnaire" originally used in rapid early action for coronary treatment (REACT) study [29]. The Arabic version was previously used among Jordanians [30]. Further, the instrument was used in different settings among different populations in Australia [13], Ireland [19], Lebanon [10], China [31], and Jordan [32]. Likewise, the instrument was translated and validated in different languages including Chinese [31], Arabic [32], and Urdu [33]. Regarding instrument's psychometrics, Buckley and colleagues [28] reported content validity and Cronbach's $\alpha$ $=0.55$ - 0.77. For the Arabic version, Eshah [30] reported moderate internal consistency for all scales $(\alpha=0.67)$. In the current study, Cronbach's $\alpha$ was 0.80 for attitudes scale and 0.70 for beliefs scale, which indicates a good internal consistency for both scales. Finally, a $70 \%$ was considered as a cut-off point for the knowledge subscale.

Data collection procedure: Approval was obtained from the ethical and scientific committee at Faculty of Nursing-The University of Jordan, and participating hospitals. Data were collected using self-reported questionnaire during February-April 2014. Head nurses of participating units served as liaison to provide lists of eligible patients, and facilitated patients' approaching. Eligible patients were invited, and those who agreed to participate received a questionnaire and anonymous cover letter in closed envelopes. Patients were informed that filling the questionnaire is considered as implied consent. Also, they were notified that participation is voluntary, and that they can withdraw at any time without affecting their quality of care. Patients were informed that there were no risks from participation and no direct benefits except helping in expanding knowledge to help future ACS patients. Upon completion, questionnaires were handed to the data collector who was available to receive them.

Data analysis: Data were screened for missing items and outliers by using central tendency measures. Outliers were also evaluated for continuous variables by boxplots and histograms. Descriptive statistics (mean and standard deviation) were used to de- 
scribe participant's characteristics for continuous variables and frequency for other variables. Pearson $r$ correlation test was used to examine the relationship between knowledge, attitudes, beliefs and perceived risk with continuous variables. Independent sample $t$ test and ANOVA test were used to examine the differences in relation to demographic variables. Assumptions of normality, Independence, Linearity and Homogeneity of Variance were tested before running the analysis, and no major violations were found.

\section{Results}

\subsection{Demographic Characteristics}

Out of 270 distributed questionnaires, 160 were returned (59\%). The relatively low response rate was due to anxiety and overwhelming perceived by patients regarding hospitalization and prognosis. As shown in Table 1, the majority of patients were men (52.5\%), married (80\%), insured (67.5\%), had school level of education (70.6\%), and with a monthly income less than 500 JOD (83.1\%). The mean age was 52.5 years (SD = 8.2 , Range $=34-64)$.

\subsection{Description of the Study Variables}

To answer the first research question, descriptive statistics were used (Table 2). The mean score of ACS knowledge was $16 \pm 3.6$ out of $26(61.5 \%$, Range $=8-24)$. Only 56 patients (35\%) had high knowledge level using $70 \%$ as a cut-off point [13]. Results showed the majority of patients (75\%) realized the importance of Aspirin during heart attack. However, only 68 (42.5\%) patients recognized that site and extent of heart attack varies according to the occluded blood vessels, and only one third of female patients knew that heart disease is the leading reason of death among women. Further, the majority of participants (95.6\%) reported chest pain/pressure as a symptom of ACS, followed by chest discomfort (91.3\%) and numbness/tingling in arm or hand (80.6\%). However, participants failed to recognize many symptoms including abdominal pain (21.3\%), heartburn/indigestion (24.4\%) and nausea/vomiting (43.8\%).

Descriptive statistics were used to answer the second research question regarding ACS attitudes (Table 3 ) and beliefs (Table 4). Participants' mean score of attitudes was $11.5 \pm 3.0$ out of 20 (Range $=5-19$ ). Analysis of attitude items revealed that the item with the highest score $(2.38 \pm 0.83)$ was "How sure are you that you could get help for yourself if you thought you were having a heart attack?". Conversely, the item with the lowest score $(2.21 \pm 0.77)$ was "How sure are you that you could recognize signs and symptoms of a heart attack on someone else?" Similarly, patients' mean score of beliefs about ACS was $24.7 \pm 4.6$ out of 40 (Range $=14-36$ ). The item that had the highest score $(3.23 \pm 0.82)$ was "Most people who have a heart attack have crushing, severe chest pain", and the item that had lowest score $(1.89 \pm 0.97)$ was "Because of the cost of medical care I would want to be absolutely sure I was having a heart attack before going to hospital".

To answer the third research question, perceived risk for future ACS event was 
Table 1. Description of sample characteristics $(\mathrm{N}=160)$.

\begin{tabular}{|c|c|c|}
\hline Variable & n (\%) & $M(S D)$ \\
\hline Age & & $52.5(8.2)$ \\
\hline Hospital type & $58(36.2)$ & \\
\hline Governmental & $51(31.9)$ & \\
\hline Education & $51(31.9)$ & \\
\hline \multicolumn{3}{|l|}{ Medical diagnosis } \\
\hline STEMI & $43(26.8)$ & \\
\hline NSTEMI & $47(29.4)$ & \\
\hline Unstable angina & $70(43.8)$ & \\
\hline \multicolumn{3}{|l|}{ Gender } \\
\hline Male & $84(52.5)$ & \\
\hline Female & $76(47.5)$ & \\
\hline \multicolumn{3}{|l|}{ Marital status } \\
\hline Single & $2(1.2)$ & \\
\hline Married & $128(80.0)$ & \\
\hline Other & $30(18.8)$ & \\
\hline \multicolumn{3}{|l|}{ Educational Level } \\
\hline Elementary & $55(34.3)$ & \\
\hline High school & $58(36.3)$ & \\
\hline University & $47(29.4)$ & \\
\hline \multicolumn{3}{|l|}{ Employment status } \\
\hline Employed & $50(31.2)$ & \\
\hline Retired & $24(15.0)$ & \\
\hline Unemployed & $86(53.8)$ & \\
\hline \multicolumn{3}{|l|}{ Income (USD) } \\
\hline$<300$ & $29(18.1)$ & \\
\hline $300-700$ & $104(65)$ & \\
\hline$>700$ & $27(16.9)$ & \\
\hline \multicolumn{3}{|l|}{ Insurance } \\
\hline Yes & $108(67.5)$ & \\
\hline No & $52(32.5)$ & \\
\hline \multicolumn{3}{|l|}{ History } \\
\hline CAD & $55(34.4)$ & \\
\hline Previous ACS information & $63(39.4)$ & \\
\hline Angina & $66(41.3)$ & \\
\hline Myocardial infarction & $30(18.8)$ & \\
\hline Cardiac surgery & $19(11.9)$ & \\
\hline Smoking & $52(32.5)$ & \\
\hline Hypercholesteremia & $74(46.3)$ & \\
\hline Hypertension & $99(61.9)$ & \\
\hline Diabetes & $70(43.8)$ & \\
\hline PCI & $48(30.0)$ & \\
\hline Family history & $111(69.0)$ & \\
\hline
\end{tabular}

STEMI: ST-segment elevation myocardial infarction, NSTEMI: Non-ST-segment elevation myocardial infarction, CAD: Coronary Artery Disease, PCI: Percutaneous Coronary Intervention. 
Table 2. Correct responses of patients regarding ACS knowledge and symptoms $(\mathrm{N}=160)$.

\begin{tabular}{|c|c|}
\hline Items & $\mathrm{n}(\%)$ \\
\hline $\begin{array}{l}\text { Most patients benefit from taking one tablet of Aspirin if } \\
\text { they experience heart attack }\end{array}$ & $120(75.0)$ \\
\hline $\begin{array}{l}\text { Heart disease is the most common cause of death in women } \\
\text { in Jordan }\end{array}$ & $111(69.4)$ \\
\hline Hospitals have treatment that reduce damage of heart attack & $100(62.5)$ \\
\hline Almost all heart attacks occur in people over age of 65 & $72(45.0)$ \\
\hline $\begin{array}{l}\text { The location and size of heart attack can vary depending on } \\
\text { which blood vessel in the heart is blocked }\end{array}$ & $68(42.5)$ \\
\hline Symptoms & $\mathrm{n}(\%)$ \\
\hline Chest pain/pressure/tightness & $153(95.6)$ \\
\hline Chest discomfort (heaviness, burning tenderness) & $146(91.3)$ \\
\hline Numbness/tingling in arm or hand & $129(80.6)$ \\
\hline Weakness/fatigue & $128(80.0)$ \\
\hline Shortness of breath/difficulty breathing & $126(78.8)$ \\
\hline Pale, ashen, loss/change of color & $123(76.9)$ \\
\hline Palpitation/rapid heart rate & $122(76.3)$ \\
\hline Sweating & $122(76.3)$ \\
\hline Arm paralysis & $116(72.5)$ \\
\hline Slurred speech & $109(68.1)$ \\
\hline Neck pain & $96(60.0)$ \\
\hline Back pain & $90(56.3)$ \\
\hline Headache & $89(55.6)$ \\
\hline Arm pain/shoulder pain & $88(55.0)$ \\
\hline Dizziness, light-headedness & $86(53.8)$ \\
\hline Loss of consciousness/fainting & $79(49.4)$ \\
\hline Jaw pain & $74(46.3)$ \\
\hline Cough & $73(45.6)$ \\
\hline Nausea/vomiting & $70(43.8)$ \\
\hline Heartburn/indigestion/stomach problem & $39(24.4)$ \\
\hline Lower abdomen pain & $34(21.3)$ \\
\hline
\end{tabular}

measured by one item stating: "compared to other people similar to your age, how likely do you think it is that you could have a heart attack in the next five years?". Mostly, patients responded with three or more indicating moderate to high perceived risk. 13 The mean score of perceived risk was $2.3 \pm 1$ (out of 5, Range $=1-4$ ). Further, 96 (60\%) patients reported low perceived risk for future ACS event, with none of the participants reported perceived risk as 5 "much more likely". 
Table 3. Description of attitudes scale.

\begin{tabular}{lcc}
\hline \multicolumn{1}{c}{ Item } & M (SD) & Range \\
\hline How sure are you that you could get help for yourself if you thought you were having a heart attack? & $2.38(0.83)$ & $1-4$ \\
How sure are you that you could get help for someone if thought they were having a heart attack? & $2.36(0.87)$ & $2.35(0.75)$ \\
How sure are you that you recognize signs and symptoms of a heart attack on yourself? & $2.24(0.78)$ & $1-4$ \\
$\begin{array}{l}\text { How sure are you that you could tell the difference between signs and symptoms of a heart attack and } \\
\text { other health problems? }\end{array}$ & $2.21(0.77)$ \\
How sure are you that you could recognize signs and symptoms of a heart attack on someone else? & $1-4$ \\
\hline
\end{tabular}

Table 4. Description of beliefs scale.

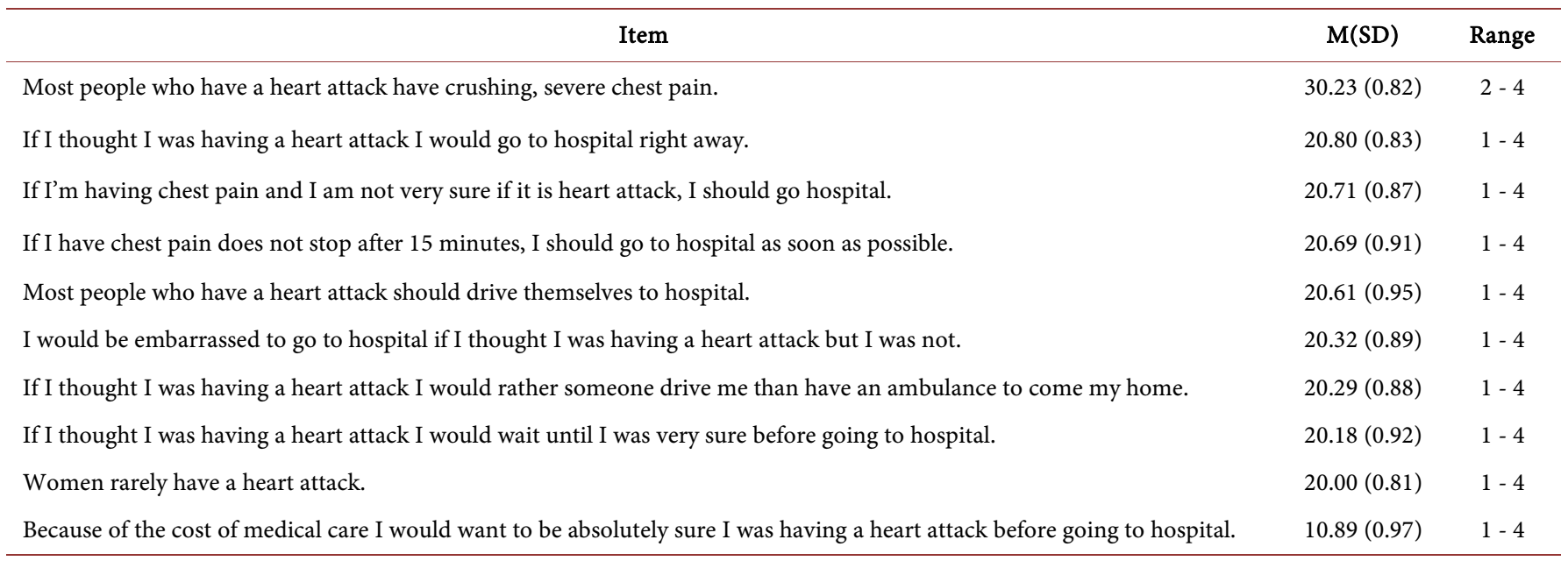

\subsection{Predictors Comparing Study Variables Based on Patient's Demographics}

The fourth question regarding relationships between study variables (ACS knowledge, attitudes, beliefs and risk perception) and demographics was answered according to the level of demographic variables. For categorical variables, independent $t$ test was used to examine the difference between categories of gender, insurance, and marital status, while ANOVA test was used for education, employment, hospital type, monthly income, and diagnosis (Table 5). For continuous variables, Person $r$ correlation was used (Table 6).

Independent sample $t$ test revealed statistically significant differences between males and female, and insured and uninsured patients regarding ACS knowledge $(\mathrm{t}(158)=$ 4.659, $\mathrm{p}=0.001),(\mathrm{t}(158)=2.507, \mathrm{p}=0.013)$, attitudes $(\mathrm{t}(158)=4.027, \mathrm{p}=0.000)$, $(\mathrm{t}(158)=1.788, \mathrm{p}=0.0 .76)$, beliefs $(\mathrm{t}(158)=3.983, \mathrm{p}=0.000),(\mathrm{t}(158)=3.370, \mathrm{p}=$ $0.001)$ and perceived risk $(t(158)=3.697, p=0.000),(t(158)=3.040, p=0.003)$. However, no significant differences were revealed based on marital status.

Analysis of variance showed statistically significant differences in patients' ACS knowledge based on their education $(\mathrm{F}(2,157)=32.1, \mathrm{p}=0.000)$, diagnosis $(\mathrm{F}(2,157)=$ $3.752, \mathrm{p}=0.026)$, hospital type $(\mathrm{F}(2,157)=4.929, \mathrm{p}=0.008)$, income $(\mathrm{F}(2,157)=13.42$, $\mathrm{p}=0.000)$, and employment $(\mathrm{F}(2,157)=9.42, \mathrm{p}=0.000)$. Also, ANOVA revealed statis- 
Table 5. Correlation among study variables.

\begin{tabular}{|c|c|c|c|c|c|c|}
\hline Variables & Knowledge & Attitudes & Beliefs & Perceived risk & Age & History \\
\hline Attitudes & $0.549^{* *}$ & 1 & & & & \\
\hline Beliefs & $0.563^{* *}$ & $0.584^{* *}$ & 1 & & & \\
\hline Perceived risk & $0.545^{\star *}$ & $0.589^{* *}$ & $0.562^{* *}$ & 1 & & \\
\hline History & $0.226^{* *}$ & $0.304^{* *}$ & $0.360^{* *}$ & $0.387^{\star *}$ & $0.509^{\star *}$ & 1 \\
\hline
\end{tabular}

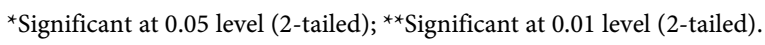

Table 6. Comparison of study variables based on categorical demographics $(\mathrm{N}=160)$.

\begin{tabular}{|c|c|c|c|c|c|}
\hline Variable & $\mathbf{n}$ & Knowledge M (SD) & Attitudes M (SD) & Beliefs M (SD) & Perceived risk $M(S D)$ \\
\hline \multicolumn{6}{|l|}{ Gender } \\
\hline Male & 84 & $17.1(3.3)^{* *}$ & $12.4(3.1)^{\star *}$ & $26(4.3)^{\star *}$ & $2.6(1.1)^{* *}$ \\
\hline Female & 76 & $14.8(2.9)$ & $10.6(2.6)$ & $23.3 \quad(4.5)$ & $2(0.9)$ \\
\hline \multicolumn{6}{|l|}{ Marital status } \\
\hline \multicolumn{6}{|l|}{ Insurance } \\
\hline Insured & 107 & $16.4(3.5)^{*}$ & $12.1(3.1)^{\star *}$ & $25.5(4.5)^{*}$ & $2.5(1.0)^{\star}$ \\
\hline Uninsured & 53 & $15.2(2.9)$ & $10.3(2.4)$ & $23 \quad(4.4)$ & $2(1.0)$ \\
\hline \multicolumn{6}{|l|}{ Education } \\
\hline University & 47 & $18.7(2.4)$ & $14.1(2.3)$ & $28.1(4.2)$ & $2.9(0.9)$ \\
\hline \multicolumn{6}{|l|}{ Income } \\
\hline$<200$ & 29 & $14.3(2.6)^{\star *}$ & $10.4(3)^{\star}$ & $22.8(3.9)^{\star \star}$ & $1.9(1.0)^{\star}$ \\
\hline $200-500$ & 104 & $15.8(3.3)^{* *}$ & $11.3(2.9)^{*}$ & $24.4(4.3)^{*}$ & $2.3(1.0)^{*}$ \\
\hline$>500$ & 27 & $18.5(2.7)$ & $13.4(2.8)$ & $27.9(4.7)$ & $2.9(0.8)$ \\
\hline \multicolumn{6}{|l|}{ Employment } \\
\hline Employed & 50 & $16.5(3.7)^{\star}$ & $12.1(3.0)^{\star}$ & $25.0(4.6) *$ & $2.2(1.0)^{\star}$ \\
\hline Unemployed & 86 & $15.1(3.1)^{\star *}$ & $10.8(2.7)^{\star *}$ & $23.5(4.1)^{\star *}$ & $2.2(1.0)^{\star *}$ \\
\hline Retired & 24 & $18.1(2.0)$ & $13.0(3.2)$ & $28.3(4.6)$ & $2.9(0.9)$ \\
\hline Educational & 51 & $15.5(3.25)^{*}$ & $11.4(2.7)^{\star}$ & $25.1(4.9)$ & $2.4(0.9)$ \\
\hline Private & 51 & $17.2(3.12)$ & $12.3(3.0)$ & $25.4(5.1)$ & $2.4(1.1)$ \\
\hline
\end{tabular}

*Significant at $\mathrm{P}<0.05 ;{ }^{*}$ Significant at $\mathrm{p}<0.01 ;$ Note: The last category of each variable was used as reference for comparison. 
tically significant differences in patients' attitudes based on their education $(\mathrm{F}(2,157)=$ $38.8, \mathrm{p}=0.000)$, diagnosis $(\mathrm{F}(2,157)=4.116, \mathrm{p}=0.017)$, hospital type $(\mathrm{F}(2,157)=3.152$, $\mathrm{p}=0.045)$, income $(\mathrm{F}(2,157)=7.99, \mathrm{p}=0.000)$, and employment $(\mathrm{F}(2,157)=7.13, \mathrm{p}=$ 0.001).

Similar statistically significant differences were revealed in patients' beliefs based on their education $(\mathrm{F}(2,157)=24.9, \mathrm{p}=0.000)$, diagnosis $(\mathrm{F}(2,157)=6.557, \mathrm{p}=0.020)$, income $(\mathrm{F}(2,157)=10.46, \mathrm{p}=0.000)$, and employment $(\mathrm{F}(2,157)=11.33, \mathrm{p}=0.000)$. Also, ANOVA showed statistically significant differences in patients' perceived risk based on their education $(\mathrm{F}(2,157)=12.5, \mathrm{p}=0.000)$, diagnosis $(\mathrm{F}(2,157)=3.731, \mathrm{p}=0.026)$, income $(\mathrm{F}(2,157)=7.49, \mathrm{p}=0.001)$, and employment $(\mathrm{F}(2,157)=4.77, \mathrm{p}=0.01)$.

Pearson $\mathrm{r}$ correlation showed significant positive correlations between knowledge score and attitudes, beliefs and perceived risk $(r=0.549, \mathrm{p}<0.01, \mathrm{r}=0.563, \mathrm{p}<0.01, \mathrm{r}$ $=0.545, \mathrm{p}<0.01)$. Moderate positive correlations were found between attitudes and both beliefs and perceived risk $(\mathrm{r}=0.584, \mathrm{p}<0.01 ; \mathrm{r}=0.589, \mathrm{p}<0.01)$, and between beliefs and perceived risk score $(\mathrm{r}=0.562, \mathrm{p}<0.01)$. Further, results revealed a low positive correlations between perceived risk and patient's age $(r=0.348, p<0.01)$. Finally, low positive correlations were found between total history and ACS knowledge $(\mathrm{r}=$ $0.226, \mathrm{p}<0.01)$, attitudes $(\mathrm{r}=0.304, \mathrm{p}<0.01)$, beliefs $(\mathrm{r}=0.360, \mathrm{p}<0.01)$, and perceived risk $(\mathrm{r}=0.387, \mathrm{p}<0.01)$. Therefore, patients who were male, insured, university-educated, retired, had income more than 500 JOD, and diagnosed with STEMI showed higher ACS knowledge, more positive attitudes and beliefs, and higher perceived risk. Moreover, patients who were recruited from the private hospital had better knowledge and attitudes than those recruited from other hospitals.

\section{Discussion}

The current study evaluated Jordanian ACS patients' knowledge, attitudes, beliefs, and perceived risk. Results found the knowledge mean score to be lower than that reported among Irish [19], and Australian, American and Kiwis patients using the same instrument [13]. Conversely, similar findings of low knowledge score were reported among Swedish [18] and Pakistani patients [20] and among public people in other studies [17] [34]. The low knowledge level could be attributed to that most of the recruited patients had elementary and high school education level. Similar conclusion was reported among Jordanian ACS patients who lacked knowledge regarding the healthy behaviors [35] [36] [37] [38] [39].

Detailed analysis of the knowledge items showed that the majority of patients recognized chest pain as the most popular ACS symptoms, followed by arm numbness and shortness of breath. However, the majority failed to recognize symptoms including abdominal pain and heartburn/indigestion. Literature were consistent with the study findings regarding the most and least recognized ACS symptoms [19] [34], which could be because patients usually reported chest pain and discomfort as traditional ACS symptom. Further, patients commonly refer less reported symptoms to gastrointestinal symptoms other than cardiac. Another explanation could be because most of patients 
gain their knowledge about ACS symptoms from their own previous experience other than in-hospital education. However, having previous ACS events does not mean to experience all related symptoms [11]. Therefore, the lack of in-hospital education for patients about ACS symptoms could be one of the possible reasons for such low knowledge among patients.

The mean score for patient's attitudes toward ACS was lower than the reported in literature [13] [19]. Detailed analysis of attitude items revealed that the attitude item that had lowest score (ability to recognize ACS symptoms on somebody) was similar to those found in literature [19] [20]. Furthermore, the item with highest score (ability to help yourself if you thought having ACS event) indicates that only $40 \%$ of patients were sure that they can help themselves at the time of ACS event. This item acquires a high mean score in comparing to other attitude items, but actually reflects inappropriate attitudes toward seeking care. Likewise, the mean score for beliefs scale was similar to the mean score reported by Dracup and colleagues [13], and lower than that reported by O'Brien and colleagues [19]. These differences could be attributed to cultural variations. In Arabic culture, decision making process usually acquired from social interaction, especially relatives and friends, rather than cognition and illness perception [40].

Detailed analysis of belief items showed that the highest score item (majority of ACS patients suffer from severe chest pain) was similar to that found in literature [19] [40]. A possible explanation is that patients commonly perceive chest pain as a serious threat that could affect their lives. However, the item that had the lowest score (the effect of healthcare costs on patient seeking care promptly) was found similar to literature [7] [17]. This could be attributed to the relatively low income for the majority of patients that makes it difficult to afford treatment costs.

Findings showed that only $43 \%$ of patients reported having high perceived risk for future ACS event, which was consistent with literature in their low level of perceived risk among respondents [13] [22]. Literature supported our findings in that patients were "optimistic" about future ACS event, which may be attributed to the lack of awareness about risk for future ACS event. This perception may result from poor communication between patients and healthcare team 16 or from negative attitudes and beliefs toward ACS [41]. Consequently, enhancing patients' ACS attitudes and beliefs, and improving communication between patients and healthcare team could be effective to improve their risk perception.

The study findings supported researchers who reported that ACS knowledge among male patients was higher than females [20], despite that some studies reported the opposite [13] [18], or equal level [19]. The lack of females' knowledge about ACS could be attributed to their negative beliefs and low risk perception,16 and their expectation that ACS is man's disease and they are concerned with other diseases like breast cancer as a major health threat [23].

Patients with high income ( $>500$ JOD) and medically insured were found to have higher ACS knowledge and perceived risk, and positive attitudes and beliefs toward ACS. In Jordan, people who were uninsured or low income cannot afford the cost of 
hospital admission due to lack of free medical treatment. Therefore, they will not adopt appropriate attitudes towards ACS symptoms and will try alternatives to relieve symptoms other than quickly seek care.

The study findings were consistent with the literature in that highly-education patients had higher knowledge and positive attitudes and beliefs [13] [19], and higher perceived risk [22]. This could be related to that educated patients may have access to ACS-related information from different sources than less educated. Similarly, findings supported literature in that older patients reported higher perceived risk than younger patients [22] [23]. This could be attributed to that elderly were more likely to have other risk factors and comorbidities, which influences their risk perception compared to younger adults who perceive themselves as healthy persons.

Patients diagnosed with STEMI were found to have higher ACS knowledge, positive attitudes and beliefs, and higher perceived risk. Conversely, O'Brien and colleagues [19] reported no differences between medical diagnoses in relation to study variables. A possible explanation is that patients diagnosed with STEMI are more likely to have previous history of ACS. Finally, results found patients in private hospital to have higher knowledge than their counterparts. Private hospitals in Jordan seem to be better in terms of patient education. Finally, lack of differences in beliefs and perceived risk could be attributed to that Jordanian patients share the same cultural background towards seeking care.

\section{Implications and Recommendations}

The study recommends developing culturally-sensitive interventional programs that consider attitudes, beliefs, and behaviors that are morally accepted by Jordanians. Moreover, it could be useful to involve patients' families in such education program, as they usually participate in decision making process in Jordanian culture. These programs should be targeted toward patients who are young, female, less-educated, uninsured, first ACS event, and lower socioeconomic status. Healthcare providers should discuss ACS symptoms with patients, with a focus on untraditional symptoms, and educate them how to properly respond to these symptoms. Policy makers for each healthcare facility should provide accessible resources like brochures and pamphlets, in addition to non-traditional methods, to disseminate awareness among patients regarding ACS symptoms. Future studies should consider psychological aspects concerning perceived risk for future ACS attack. Also, integration of qualitative research to explore perceived risk may generate new knowledge and increase depth of understanding.

\section{Limitations of the Study}

This study could not eliminate the chance of selection bias due to using non-random selection, which may reduce the generalizability of findings. Therefore, future studies are recommended to use random sampling for patients' selection. Finally, perceived risk was measured by one item scale, which could give inaccurate estimation of perceived risk level. Adoption of a valid and reliable scale that measures patients' perceived 
risk event is highly recommended.

\section{Conclusion}

This study explored ACS knowledge, attitude, beliefs and perceived risk among Jordanian patients, who reported less optimum knowledge, inappropriate attitudes and beliefs and low perceived risk. One-on-one interventional program geared toward younger patients who are female, less educated, uninsured, first ACS event and lower socioeconomic status might be effective to improve knowledge, attitudes, beliefs and perceived risk.

\section{Acknowledgements}

The authors would like to acknowledge the University of Jordan for funding this study. Also, thanks are extended to the directors of nursing who granted access to participants in their organizations, and for the participants for their valuable contribution.

\section{References}

[1] Nichols, M., Townsend, N., Luengo-Fernandez, R., et al. (2012) European Cardiovascular Disease Statistics. European Heart Network, Brussels, European Society of Cardiology, Sophia Antipolis.

[2] American Heart Association (2010) Heart Disease \& Stroke Statistics 2010 Update At-Aglance. Circulation, 121, 246-215.

[3] Ramah, T. (2010) Cardiovascular Disease in the Asia Middle East Region: Global Trends and Local Implications. Asia Pacific Journal of Public Health, 22, 83-89. https://doi.org/10.1177/1010539510373034

[4] Jordanian Ministry of Health (2010) Mortality Report. http://www.moh.gov.jo

[5] World Health Organization (2012) Jordan: WHO Statistical Profile. http://www.who.int/gho/countries/jor.pdf

[6] Lloyd-Jones, D., Adams, R., Carnethon, M., et al. (2009) Heart Disease and Stroke Statistics-2009 Update a Report from the American Heart Association Statistics Committee and Stroke Statistics Subcommittee. Circulation, 119, e21-e181. https://doi.org/10.1161/CIRCULATIONAHA.108.191261

[7] McKinley, S., Moser, D. and Dracup, K. (2000) Treatment-Seeking Behavior for Acute Myocardial Infarction Symptoms in North America and Australia. Heart \& Lung, 29, 237 247. https://doi.org/10.1067/mhl.2000.106940

[8] Moser, D., Kimble, L., Alberts, M., et al. (2006) Reducing Delay in Seeking Treatment by Patients with Acute Coronary Syndrome and Stroke a Scientific Statement from the American Heart Association Council on Cardiovascular Nursing and Stroke Council. Circulation, 114, 168-182. https://doi.org/10.1161/CIRCULATIONAHA.106.176040

[9] Taylor, D., Garewal, D., Carter, M., Bailey, M. and Aggarwal, A. (2005) Factors That Impact upon the Time to Hospital Presentation Following the Onset of Chest Pain. Emergency Medicine Australasia, 17, 204-211. https://doi.org/10.1111/j.1742-6723.2005.00724.x

[10] Noureddine, S., Adra, M., Arevian, M., et al. (2006) Delay in Seeking Health Care for Acute Coronary Syndromes in a Lebanese Sample. Journal of Transcultural Nursing, 17, 341-348. https://doi.org/10.1177/1043659606291544

[11] Thuresson, M., Jarlöv, M., Lindahl, B., Svensson, L., Zedigh, C. and Herlitz, J. (2007) 
Thoughts, Actions, and Factors Associated with Prehospital Delay in Patients with Acute Coronary Syndrome. Heart \& Lung, 36, 398-409.

https://doi.org/10.1016/j.hrtlng.2007.02.001

[12] Riegel, B., McKinley, S., Moser, D., Meischke, H., Doering, L. and Dracup, K. (2007) Psychometric Evaluation of the Acute Coronary Syndrome (ACS) Response Index. Research in Nursing \& Health, 30, 584-594. https://doi.org/10.1002/nur.20213

[13] Dracup, K., McKinley, S., Doering, L., et al. (2008) Acute Coronary Syndrome: What Do Patients Know? Archives of Internal Medicine, 168, 1049-1054. https://doi.org/10.1001/archinte.168.10.1049

[14] Moser, D., McKinley, S., Dracup, K. and Chung, M. (2005) Gender Differences in Reasons Patients Delay in Seeking Treatment for Acute Myocardial Infarction Symptoms. Patient Education and Counseling, 56, 45-54. https://doi.org/10.1016/j.pec.2003.11.011

[15] Pattenden, J., Watt, I., Lewin, R. and Stanford, N. (2002) Decision Making Processes in People with Symptoms of Acute Myocardial Infarction: Qualitative Study. British Medical Journal, 324, 1006. https://doi.org/10.1136/bmj.324.7344.1006

[16] Hart, P. (2005) Women's Perceptions of Coronary Heart Disease: An Integrative Review. Journal of Cardiovascular Nursing, 20, 170-176. https://doi.org/10.1097/00005082-200505000-00008

[17] Hwang, S., Ryan, C. and Zerwic, J. (2008) Korean Immigrants' Knowledge of Heart Attack Symptoms and Risk Factors. Journal of Immigrant and Minority Health, 10, 67-72. https://doi.org/10.1007/s10903-007-9053-y

[18] Henriksson, C., Larsson, M., Arnetz, J., et al. (2011) Knowledge and Attitudes toward Seeking Medical Care for AMI-Symptoms. International Journal of Cardiology, 147, 224227. https://doi.org/10.1016/j.ijcard.2009.08.019

[19] O’Brien, F., O’Donnell, S., McKee, G., Mooney, M. and Moser, D. (2013) Knowledge, Attitudes, and Beliefs about Acute Coronary Syndrome in Patients Diagnosed with ACS: An Irish Cross-Sectional Study. European Journal of Cardiovascular Nursing, 12, 201-208.

[20] Khan, M., Jafary, F., Faruqui, A., et al. (2007) High Prevalence of Lack of Knowledge of Symptoms of Acute Myocardial Infarction in Pakistan and Its Contribution to Delayed Presentation to the Hospital. BMC Public Health, 7, 284.

https://doi.org/10.1186/1471-2458-7-284

[21] Henriksson, C., Lindahl, B. and Larsson, M. (2007) Patients' and Relatives' Thoughts and Actions during and after Symptom Presentation for an Acute Myocardial Infarction. European Journal of Cardiovascular Nursing, 6, 280-286.

[22] Ammouri, A., Neuberger, G., Mrayyan, M. and Hamaidah, S. (2010) Perception Risk of Coronary Heart Disease among Jordanian. Journal of Clinical Nursing, 20, 197-203. https://doi.org/10.1111/j.1365-2702.2010.03192.x

[23] Mosca, L., Ferris, A., Fabunmi, R. and Robertson, R. (2004) Tracking Women's Awareness of Heart Disease an American Heart Association National Study. Circulation, 109, 573-579. https://doi.org/10.1161/01.CIR.0000115222.69428.C9

[24] Jordanian Department of Statistics (2012) Jordan Statistical Yearbook. http://www.dos.gov.jo

[25] Jordanian Ministry of Health (2013) Annual Report. http://www.moh.gov.jo

[26] Association for Community Health Improvement (2013) Trends in Hospital-Based Population Health Infrastructure: Results from an Association for Community Health Improvement and American Hospital Association Survey. Health Research and Educational Trust, Chicago. www.healthycommunities.org 
[27] Cohen, J. (1992) Quantitative Methods in Psychology: A Power Primer. Psychological Bulletin, 112, 155-159. https://doi.org/10.1037/0033-2909.112.1.155

[28] Buckley, T., McKinley, S., Gallagher, R., Dracup, K., Moser, D. and Aitken, L. (2007) The Effect of Education and Counseling on Knowledge, Attitudes and Beliefs about Responses to Acute Myocardial Infarction Symptoms. European Journal of Cardiovascular Nursing, 6, 105-111.

[29] Leupker, R., Raczynski, J., Osganian, S., et al. (2000) Effect of a Community Intervention on Patient Delay and Emergency Medical Service Use in Acute Coronary Heart Disease: The Rapid Early Action for Coronary Treatment (REACT) Trial. JAMA, 284, 60-67. https://doi.org/10.1001/jama.284.1.60

[30] Eshah, N., Bond, A. and Froelicher, E. (2010) The Effects of a Cardiovascular Disease Prevention Program on Knowledge and Adoption of a Heart Healthy Lifestyle in Jordanian Working Adults. European Journal of Cardiovascular Nursing, 9, 244-253.

[31] Li, P., Lee, D. and Doris, S. (2014) Psychometric Evaluation of the Symptoms of Acute Coronary Syndromes Inventory in Chinese Patients with Acute Coronary Syndromes. European Journal of Cardiovascular Nursing, 13, 295-303.

[32] Eshah, N. (2013) Seeking Medical Attention among Jordanian Patients with Acute Myocardium Infarction. The Meeting of the 1 st Annual International Interdisciplinary Conference, Azores, 24-26 April 2013, 753-761.

[33] Allana, S., Ali, T., Khowaja, K., Khan, A. and Moser, D. (2013) Validity and Reliability Testing: Urdu Translated Modified Response to Symptoms Questionnaire. Journal of the College of Physicians and Surgeons Pakistan, 23, 383-387.

[34] Cytryn, K., Yoskowitz, N., Cimino, J. and Patel, V. (2009) Lay Public's Knowledge and Decisions in Response to Symptoms of Acute Myocardial Infarction. Advances in Health Sciences Education, 14, 43-59. https://doi.org/10.1007/s10459-007-9085-Z

[35] Mosleh, S. and Darawad, M. (2015) Patients' Adherence to Healthy Behavior in Coronary Heart Disease: Risk Factor Management among Jordanian Patients. Journal of Cardiovascular Nursing, 30, 471-478. https://doi.org/10.1097/JCN.0000000000000189

[36] Darawad, M., Alfasfos, N., Saleh, Z., Saleh, A. and Hamdan-Mansour, A. (2016) Predictors of Delay in Seeking Treatment by Jordanian Patients with Acute Coronary Syndrome. International Emergency Nursing, 26, 20-25. https://doi.org/10.1016/j.ienj.2015.09.003

[37] Hammad, S., Darawad, M., Haourani, E. and Demeh, W. (2015) Predictors of Glycated Hemoglobin among Jordanian Diabetic Patients. Iranian Journal of Public Health, 44, 1482-1491.

[38] Darawad, M. and Khalil, A. (2012) Jordanian Dialysis Patients' Perceived Exercise Benefits and Barriers: A Correlation Study. Rehabilitation Nursing, 38, 315-322. https://doi.org/10.1002/rnj.98

[39] Khalil, A., Darawad, M., Eljamal, E., Mansour, A. and Abed, M. (2012) Predictors of Dietary and Fluid Non-Adherence in Jordanian Patients with End-Stage Renal Disease Receiving Hemodialysis: A Cross-Sectional Study. Journal of Clinical Nursing, 22, 127-136. https://doi.org/10.1111/j.1365-2702.2012.04117.x

[40] Al-Hassan, M. and Omran, S. (2005) The Effects of Health Beliefs on Health Care Seeking Decisions of Jordanian Patients with Myocardial Infarction Symptoms. International Journal of Nursing Practice, 11, 13-20. https://doi.org/10.1111/j.1440-172X.2005.00497.x

[41] Antonovsky, A. (1987) Unraveling the Mystery of Health: How People Manage Stress and Stay Well. Jossey-Bass, San Francisco. 
Submit or recommend next manuscript to SCIRP and we will provide best service for you:

Accepting pre-submission inquiries through Email, Facebook, LinkedIn, Twitter, etc.

A wide selection of journals (inclusive of 9 subjects, more than 200 journals)

Providing 24-hour high-quality service

User-friendly online submission system

Fair and swift peer-review system

Efficient typesetting and proofreading procedure

Display of the result of downloads and visits, as well as the number of cited articles

Maximum dissemination of your research work

Submit your manuscript at: http://papersubmission.scirp.org/

Or contact health@scirp.org 